\title{
Research on Wear Resistance of Polymeric Composite Materials Based on Micro- particles from Tyre Recyclation Process
}

\author{
Miroslav Müller ${ }^{1}$, Anna Rudawska², Martin Tichý1 ${ }^{1}$, Viktor Kolár ${ }^{1}$, Monika Hromasováa \\ ${ }^{1}$ Czech University of Life Sciences Prague, Department of Material Science and Manufacturing Technology, Ka- \\ mýcká 129, 16500 Praha 6 - Suchdol, Czech Republic. E-mail: muller@tf.czu.cz, martintichy@tf.czu.cz, vko- \\ lar@tf.czu.cz \\ 2Politechnika Lubelska, Faculty of Mechanical Engineering, Lublin, Poland. E-mail: a.rudawska@pollub.pl \\ ${ }^{3}$ Czech University of Life Sciences Prague, Department of Electrical Engineering and Automation, Kamýcká 129, \\ 16500 Praha 6 - Suchdol, Czech Republic. E-mail: hromasova@tf.czu.cz
}

\begin{abstract}
A huge amount of waste comes into being from tyres which cannot already be used for their purpose. There are many ways how to utilize this waste but material recyclation is a priority. Waste tyre rubbers can be processed into a form of granulate which can be used into polymeric composite materials. This research deals with possibilities of tyre waste composite material utilization in areas distinguished for wear. The aim of the research was an assessment of a usage possibility of rubber powder (RP) coming into being from tyre recyclation process as a filler into a thermosetting matrix from firm Havel Composite applied into composite boards made by a vacuum infusion. The research focused on an evaluation of wear by friction against loosely fixed abrasive particles according to GOST 23.208-79, hardness and interaction of the matrix and the reinforcement by means of SEM analysis of the polymeric composite materials reinforced with waste microparticles arisen from tyre recyclation process. Research results proved a positive influence of the filler on the improvement of the wear resistance depending on the size of active rubber powder.
\end{abstract}

Keywords: Hardness, Mass Loss, Wear Track, Loosely Fixed Abrasive Particles, SEM

\section{Introduction}

The global consumer problem is the emergence of waste that needs to be handled and used as efficiently as possible [1]. A biological waste is treated relatively simply $[2,3]$. Worse situation comes with synthetic waste. Large amount of tyre waste comes from e.g. traffic transport, construction and agriculture vehicles, where the tyres cannot fulfil their function $[4,5]$. The lifetime of tyres is relatively low, and it is given by intensive operation or by degradation process, which cause the wear and other defects. This fact leads to a significant global production of tyre waste $[6,7,8]$. The most leading recycling process of the waste tyre is milling and crushing, which produce granulate for next use $[7,8]$. This granulate cannot be repeatedly vulcanized, therefore the granulate is used in composite production $[1,7]$. In general, composite materials are used in various products. Composite materials contain a matrix and a reinforced phase (filler) which improves mechanical properties and possibly decreases costs of the matrix. The mechanical properties of the matrix are usually improved by reinforced phase in a fibre form as fabric $[9,10,11,12]$. The use of a reinforcing phase (filler) in a form of particles is rather a price reduction, tribological properties improvement or hardness improvement against the matrix $[13,14$,
$15,16,17,18]$. However, it is always important to examine an interaction between filler and matrix which is necessary for right function of the composite material.

The aim of the research was an assessment of usage possibility of the active rubber powder (ARP) coming into being from tyre recycle process as the filler into the thermosetting matrix from firm Havel Composite applied into composite boards made by a vacuum infusion. The research focused on an evaluation of wear by friction against loosely fixed abrasive particles according to GOST 23.208-79, hardness and interaction of the matrix and the reinforcement by means of SEM analysis of the polymeric composite materials reinforced with waste microparticles arisen from tyre recycle process.

\section{Materials and methods}

The research evaluated the polymeric composite material based on microparticles from tyre recycling process. The rubber particles were provided by Czech leading producer of tyre recycling. For the research two fraction types of the rubber powder marked as $(\mathrm{RP})$ in sizes $0.0-0.4 \mathrm{~mm}$ and $0.4-0.8 \mathrm{~mm}$ were used (Fig. $1 \mathrm{C}$-below). This rubber powder was produced by fine milling of waste tyre. 
For production of a polymeric composite material with microparticles RP the matrix by Havel Composite LH 388 with the hardener H 282 was used.

Test samples for evaluation of the wear resistance were produced in dimensions $25 \times 25 \times 5 \mathrm{~mm}$ by vacuum infusion according to GOST 23.208-79 (Ensuring of wear resistance of products. Wear resistance. Testing of materials by friction against loosely fixed abrasive particles). The filler RP was added in 30 vol. $\%$. This concentration was proved as limited from previous researches [1].

The research of the wear resistance was performed according to standard GOST 23.208-79 on testing device with rubber wheel and abrasive particles (float sand Otava with fraction dimensions from 0.2 to 0.3 $\mathrm{mm}$ ) by loading of the test sample from 700 to 1600 g. The wear testing process is evident from fig. $1 \mathrm{~A}$. The wear evaluation was based on a wear track and a mass loss measured on analytical scale Kern. The wear track was determined on a basis of the rubber wheel speed i.e. after $1000 \mathrm{rpm}$. The test samples after wear process are evident from fig. $1 \mathrm{~B}$ and $\mathrm{C}$.

The hardness of test samples was measured according to CSN EN ISO 2039-1 by a ball of a diameter 5 $\mathrm{mm}$, loading force $358 \mathrm{~N}$ on device DuraJet G5 Rockwell Hardness tester. A size and a shape of the filler $\mathrm{RP}$, the wear process and the interaction between the matrix and the filler RP were evaluated by SEM analysis.

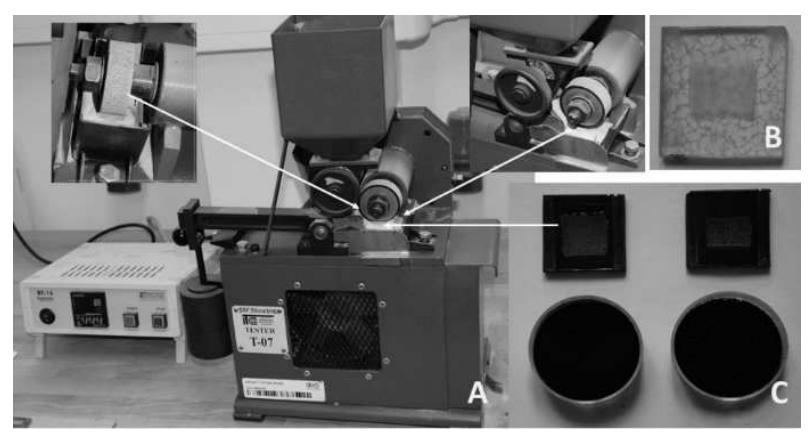

Fig. 1 Wear testing process: A:Device Tester T-07, ITC PIB Institution of Technology Radom and control device BT-

16 Controller with detailed view on wear process, B: Test sample after wear process - matrix, $C$ : Test sample after wear process - composite RP0.0-0.4 (upper left), RP0.4-0.8 (upper right) and filler RP0.0-0.4 (below left), RP0.4-0.8 (below right)

\section{Results and discussion}

The filler was analysed by Gwyddion program from SEM images. The results are listed on fig. 2 which records a size representation on the reference sample of the filler marked as RP0.0-0.4 and RP0.40.8. The filler RP0.0-0.4 had average dimensions 99.38 $\pm 81.40 \mu \mathrm{m}$ and the filler RP0.4-0.8 had average dimensions $571.80 \pm 171.83 \mu \mathrm{m}$. From fig. 2 it is evident that the filler RP0.0-0.4 represents a significant ratio of microparticles smaller than $100 \mu \mathrm{m}$.

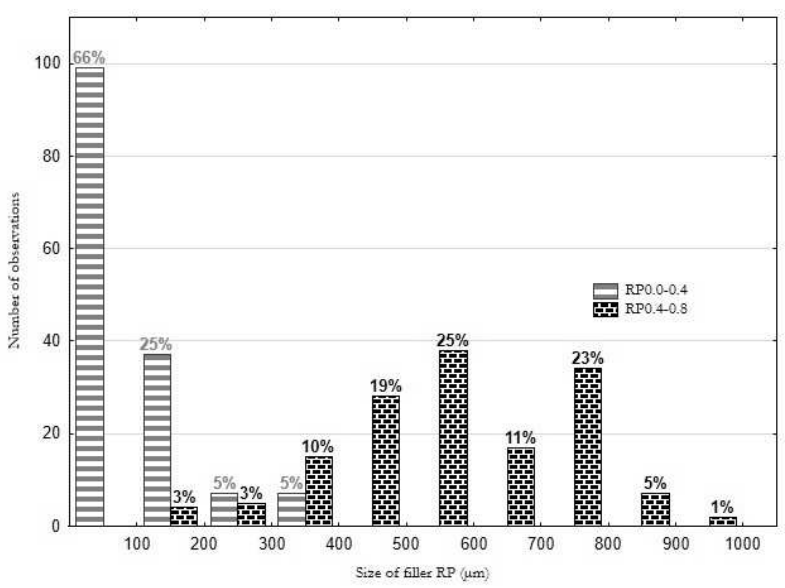

Fig. 2 Frequency bistogram with microparticles of filler $R P$ from tyre recycle process

By more detailed SEM analysis a shape of the filler $\mathrm{RP}$ was determined which is evident from fig. 3. Especially the filler RP0.0-0.4 shows an irregular surface, which is evident from fig. $3 \mathrm{~A}$ and $\mathrm{B}$. Other authors came to similar conclusions $[1,8]$. The filler RP0.4-0.8 shows a regular surface, which is visible from fig. $3 \mathrm{C}$ and $\mathrm{D}$.

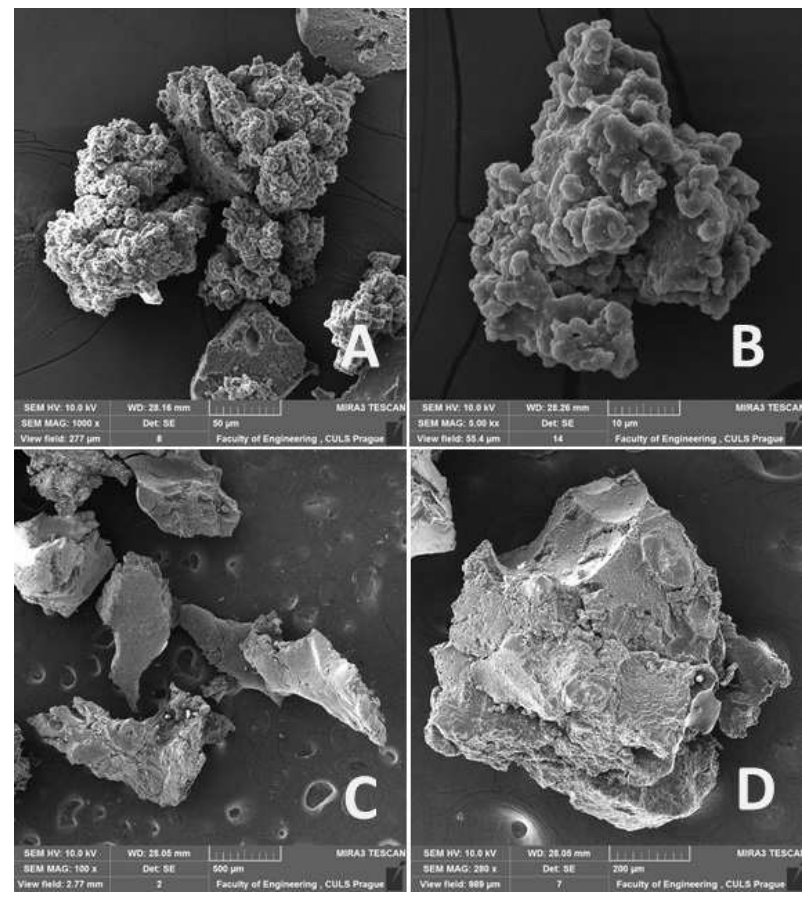

Fig. 3 SEM images of filler RP: A: Filler RPO.0-0.4 (MAG 1000x), B: Detailed view on irregular surface of filler RP0.0-0.4 (MAG 5.00kx), C: Filler RP0.4-0.8 MAG 100x), D: Detailed view on surface of filler RP0.4-0.8 (MAG 280x)

The roughness was measured before the wear process. The roughness of the matrix was $\mathrm{Ra} 0.60 \pm 0.18$ $\mu \mathrm{m}, \mathrm{Rz} 3.10 \pm 0.33 \mu \mathrm{m}$, the roughness of the composite RP0.0-0.4 was $\mathrm{Ra} 0.38 \pm 0.06 \mu \mathrm{m}, \mathrm{Rz} 2.24 \pm 0.29$ 
$\mu \mathrm{m}$ and of the composite RP0.4-0.8 was $\mathrm{Ra} 0.20 \pm$ $0.06 \mu \mathrm{m}, \mathrm{Rz} 0.92 \pm 0.19 \mu \mathrm{m}$. From the results it is evident that the surface of composite materials reports lower value of tested roughness parameters.

The matrix and composite materials wear progression at various loadings is evident on fig. 4 and 5 i.e. various loading forces on the test sample to the rubber wheel. The wear progression shows a same linear trend at various loading forces on test sample to rubber wheel. The results show a linear increase of the mass loss at test samples. The composite reported best results at both loadings $1600 \mathrm{~g}$ and $700 \mathrm{~g}$ at filler RP0.4-0.8, i.e. the composite reinforced with microparticles RP with fraction size $571.80 \pm 171.83 \mu \mathrm{m}$. Lower wear resistance was reported by the composite material with the filler RP of the fraction size $99.38 \pm$ $81.40 \mu \mathrm{m}$. This composite material reported lower wear resistance than the matrix.

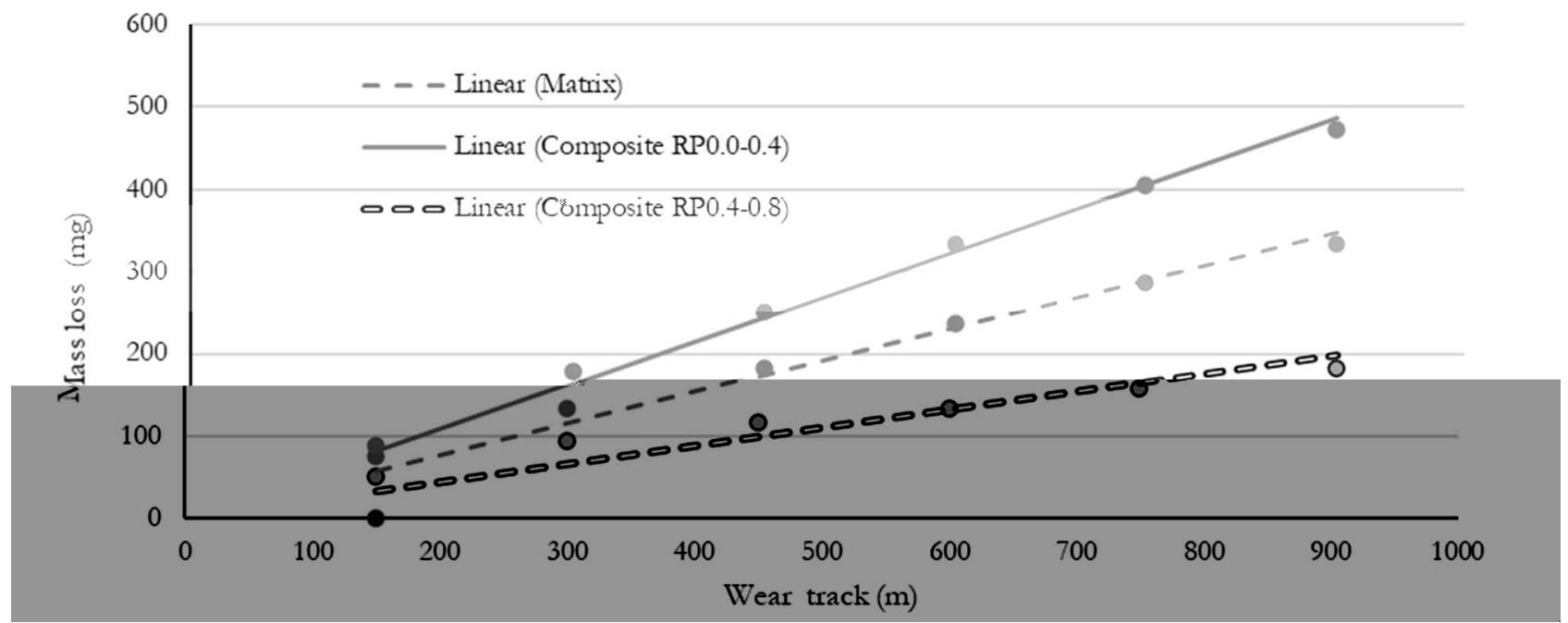

Fig. 4 Wear progression at loading $1600 \mathrm{~g}$

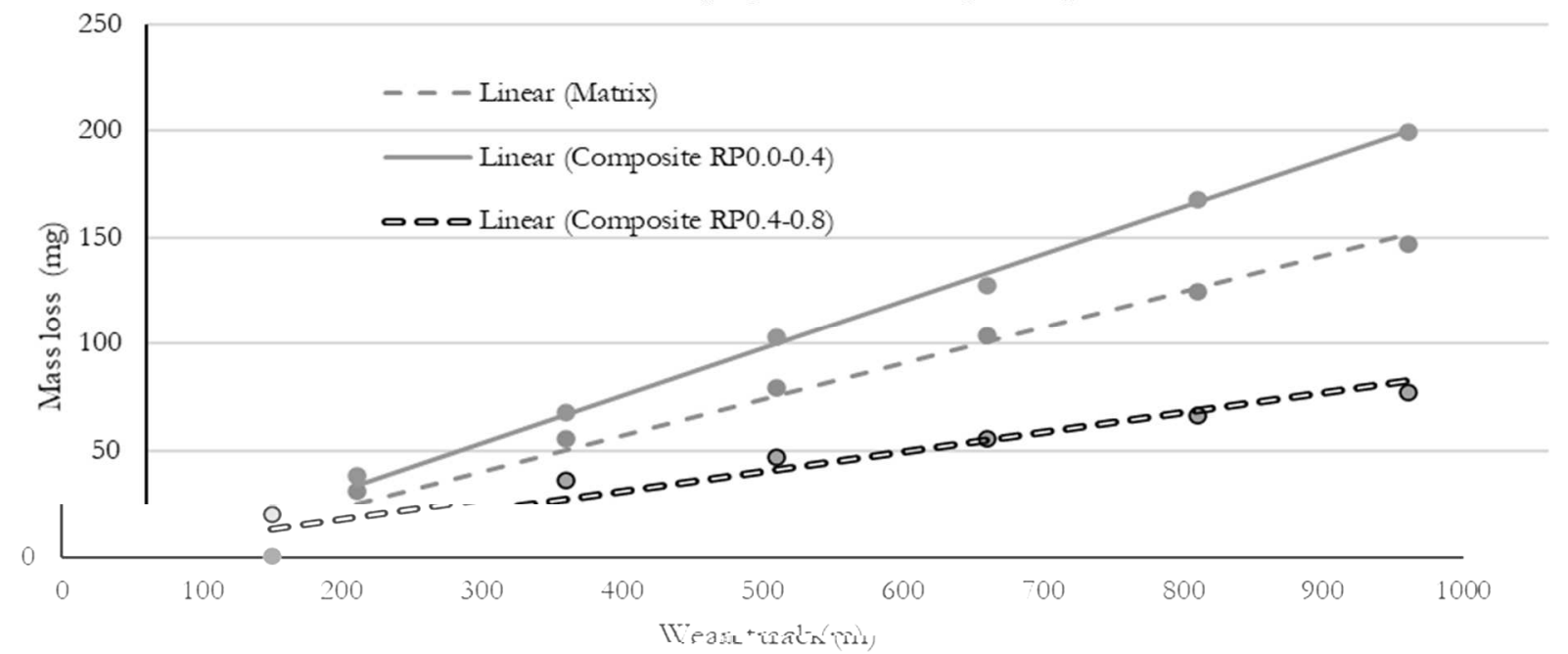

Fig. 5 Wear progression at loading $700 \mathrm{~g}$

The dependence tightness is measured by a determination index and takes values from 0 to 1 . The closer values approach 1 , the stronger dependence is. The determination index $\mathrm{R}^{2}$ gives the percentage influence of the wear track on the mass loss. The dependence tightness, the functional equations of the wear (mass loss) and the wear track are listed in tab. 1.

The matrix and the composite materials were tested between themselves according to ANOVA F-test in significant level 0.05. The results are evident from fig. 6 . The null hypothesis $\mathrm{H} 0$ was referred when there is no statistically significant difference between indivi- dual data: $\mathrm{p}>0.05$. The hypothesis $\mathrm{H} 0$ was not confirmed for any loading of test samples i.e. various intensity of loading force on test samples to rubber wheel (700 g, $\mathrm{p}=0.001$ and $1600 \mathrm{~g}, \mathrm{p}=0.001)$, there is a significant difference in the significant level 0.05 between tested materials (matrix, composite RP0.0-0.4 and RP0.4-0.8).

On fig. 6 there are total results of the wear where it is evident that the highest wear resistance is at the composite material with the filler RP0.4-0.8 at loading $700 \mathrm{~g}$. There was a significant dispersion of the results at higher loads. 
Tab. 1 Functional equations of mass loss dependence on wear track of composite material with its determination index

\begin{tabular}{llll}
\hline Designation & Wear test - Mass $(\mathrm{g})$ & Functional equation & Determination index \\
\hline Matrix & 1600 & $\mathrm{y}=0.3862 \mathrm{x}$ & 0.981 \\
\hline Composite RP0.0-0.4 & 1600 & $\mathrm{y}=0.5415 \mathrm{x}$ & 0.994 \\
\hline Composite RP0.4-0.8 & 1600 & $\mathrm{y}=0.8413 \mathrm{x}$ & 0.841 \\
\hline Matrix & 700 & $\mathrm{y}=0.1685 \mathrm{x}$ & 0.989 \\
\hline Composite RP0.0-0.4 & 700 & $\mathrm{y}=0.2222 \mathrm{x}$ & 0.996 \\
\hline Composite RP0.4-0.8 & 700 & $\mathrm{y}=0.0919 \mathrm{x}$ & 0.916 \\
\hline
\end{tabular}

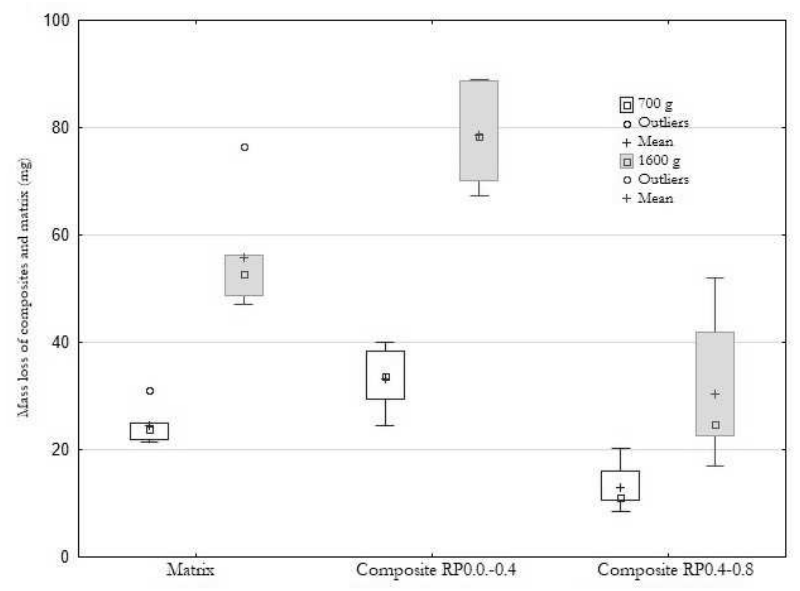

Fig. 6 Statistical comparison of total wear results

The SEM analysis proved a different behaviour of tested materials at the wear process. The surface of the wear matrix is on fig. 7. From fig. $7 \mathrm{~A}$ the surface without the wear and the surface after the wear are evident. From fig. $7 \mathrm{C}$ the detailed view on a transition area i.e. the surface without the wear and the surface after the wear is evident. The wear surface shows craters created by abrasive grains of floated sand. Fig. 7 $\mathrm{B}$ shows the wear surface in the middle part of the wear track which is evident on fig. $1 \mathrm{C}$.

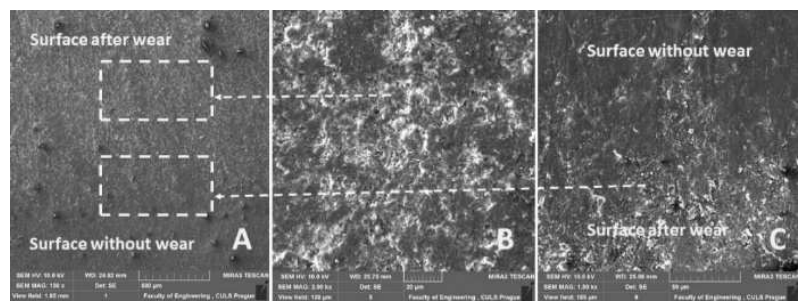

Fig. 7 SEM images of tested matrix surface - loading 1600 g: A: Transition surface area before and after wear $(M A G$ 150x), B: Wear surface (MAG $2.00 \mathrm{kx}$ ), C: Detailed view on transition area before and after wear (MAG $1.50 \mathrm{kx})$

The wear surface of the composite material RP0.40.8 is on fig. 8. From fig. $8 \mathrm{~A}$ the wear track is evident. From fig. $8 \mathrm{~B}$ the surface without wear and the surface after wear are evident. From fig. $8 \mathrm{C}$ the detailed view on the wear surface is evident. The wear surface did not show craters created by abrasive grains of floated sand. The abrasive grains wore the matrix and the RP fillers stayed on the surface until they were broken up from the matrix (fig. $8 \mathrm{~A}, \mathrm{~B}$ and $\mathrm{C}$ ).
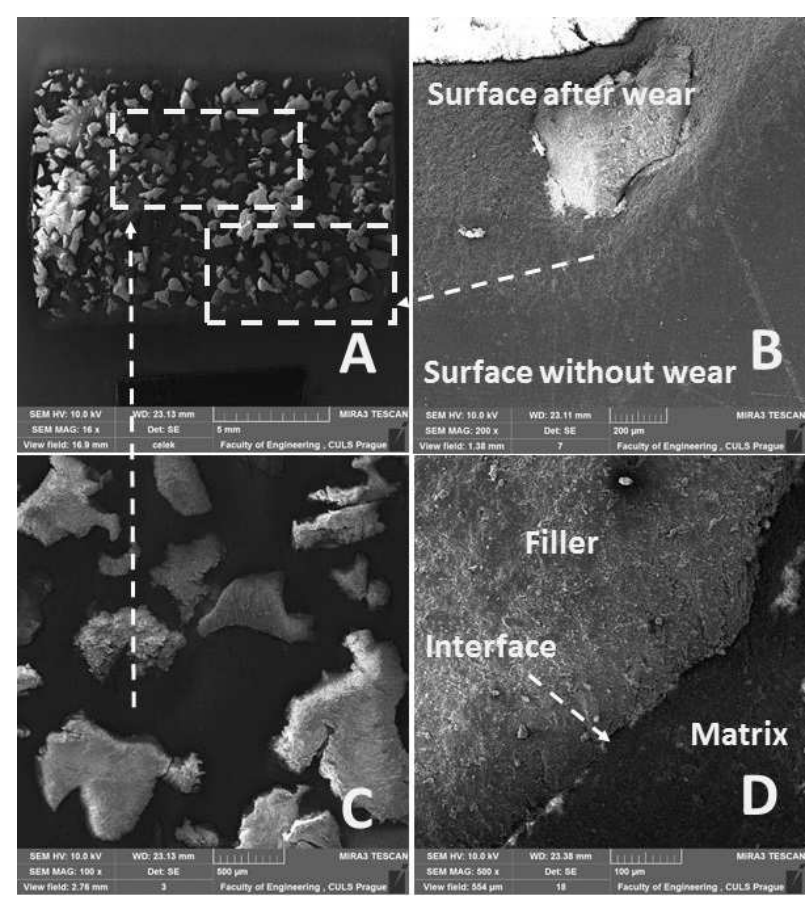

Fig. 8 SEM images of tested composite surface RP0.4-0.8 loading $1600 \mathrm{~g}$ : A: Total view on wear surface $(M A G 16 x)$, B: Transmission area before and after wear process $(M A G$ 200x), C: Wear surface (MAG 100x), D: Detailed view on matrix and filler interaction ( $M A G 500 x)$

This fact significantly increases the wear resistance. The microparticle filler RP showed good adhesion strength to the matrix even there is evident lower interaction between the matrix and the filler (fig. $8 \mathrm{D}$ ). The interaction between the filler and the matrix is influenced by the wettability which interfaces the cohesion strength i.e. inside strength of the composite layer $[15,16,17,19]$. This lower interaction on interface of the matrix and the filler (fig. $8 \mathrm{~B}$ and $\mathrm{D}$ ) is not evident on total circuit of microparticle RP (fig. $8 \mathrm{~B}$ ). It is possible to conclude from this that it is not lower wettability of microparticle RP. It is probably by influencing microparticle RP deformation and its delamination from the matrix. Same conclusions were made in 
other studies dealing with usage of tyre recycle $[1,8$, $20,21,22,23]$.

The composite material RP0.0-0.4 worn surface is on fig. 9. From fig. $9 \mathrm{~A}$ the wear track is evident, which created the irregular surface. From fig. 9 B the surface without wear and the surface with the wear is evident. On the wear surface the microparticles RP are evident. From fig. $9 \mathrm{C}$ the detailed view on the wear surface is evident, which has irregular crater surface. There was considerable mass loss at the wear process, which is evident from fig. 9 C. This fact significantly decreases the wear resistance. An interaction between the matrix and the filler is evident on fig. $9 \mathrm{D}$.

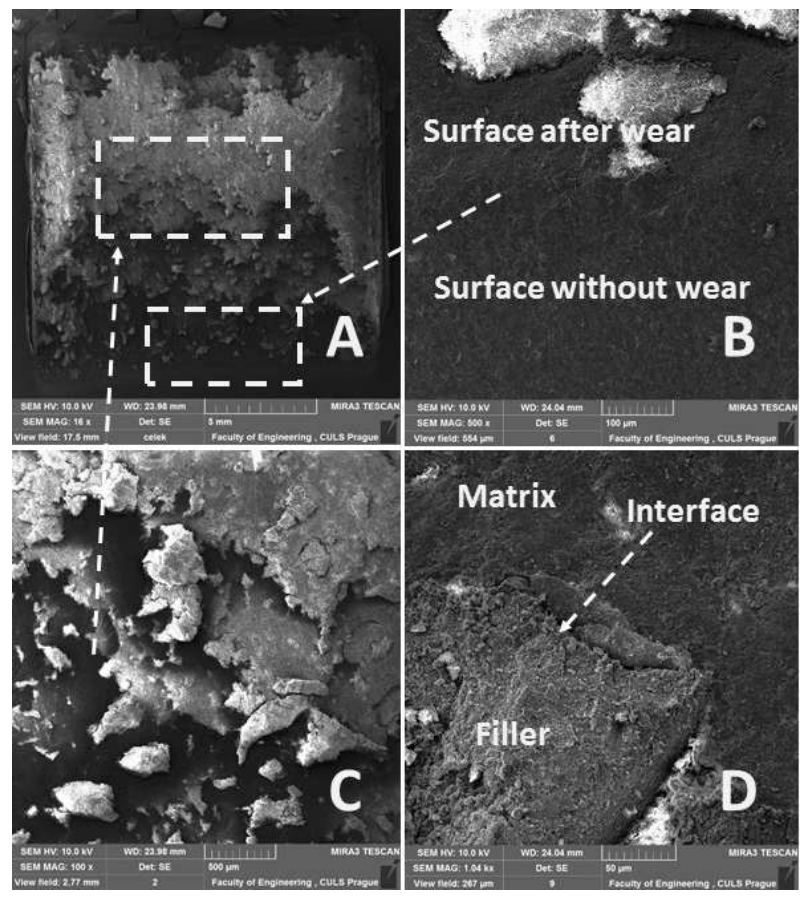

Fig. 9SEM images of tested composite surface RPO.0-0.4loading $1600 \mathrm{~g}:$ A: Total view on wear process (MAG 16x), $B:$ Transmission area of surface before and after wear process (MAG 500x), C: Wear surface (MAG 100x), D: Detailed view on matrix and filler $R P$ interaction (MAG 1.04kx)

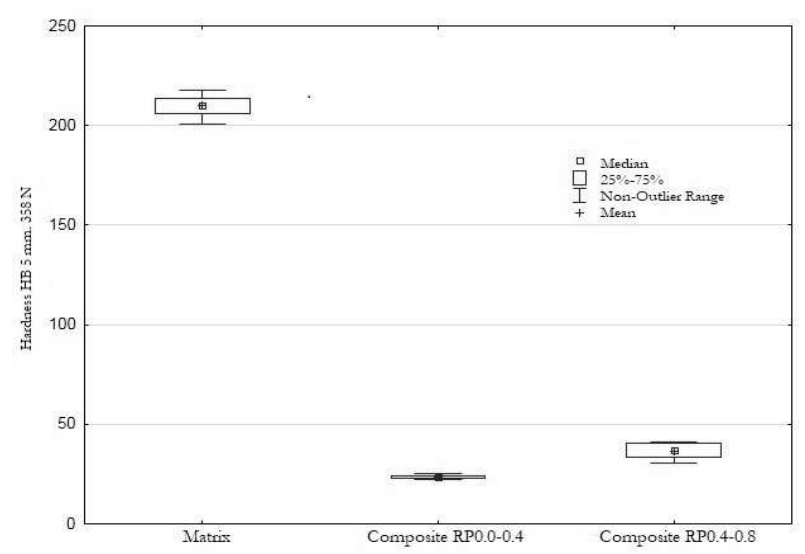

Fig. 10 Hardness of tested material by HB method

The results of composite materials and matrix hardness are evident from fig. 10. The matrix shows a significant difference of the hardness against the composite materials. The filler RP in matrix significantly decreases the hardness of tested materials. The hardness decrease of the composite material is caused by use of the filler based on elastomeric particles. From the results it is evident that there is no direct proportion between the hardness and the wear resistance as at steel. Therefore, it cannot be said that the hardness is directly proportional to the wear resistance. In terms of the statistical testing it is possible to state that it is statistically inhomogeneous groups i.e. there is the significant difference between the composite material and the matrix in the significant level $0.05(\mathrm{p}=0.000)$.

Results of the research proved that the elastomeric product from tyre waste recycle process can be used in the material field [7]. One of the possibilities is the composite material production based on thermosetting matrix.

\section{Conclusion}

The research deals with usage possibility of the filler RP from waste tyre recycle process into polymeric composite materials with thermosetting resin matrix. In the research two fractions of the filler in the interval from 0 to $400 \mu \mathrm{m}$ and from $400 \mu \mathrm{m}$ to $800 \mu \mathrm{m}$ (significant representation of this fraction) were used. The results of the research confirmed that the composite material RP0.4-0.8 showed good wear resistance by method of use the rubber wheel and the abrasive according to GOST 23.208-79. The elastic rubber microparticles RP can absorb internal stress on the interface of the matrix and the filler.

\section{Acknowledgement}

Supported by Internal grant agency of Faculty of Engineering, Czech University of Life Sciences Prague (no. 31140/1312/313108)

\section{References}

[1] MÜLLER, M., VALÁŠEK, P., RUDAWSKA, A., \& CHOTÉBORSKÝ, R. (2018). Effect of active rubber powder on structural two-component epoxy resin and its mechanical properties. Journal of adhesion science and Technology, Vol. 32, No. 14, pp. 1531-1547.

[2] BRUNEROVÁ, A., MÜLLER, M., ŠLEGER, V., AMBARITA, H., \& VALÁŠEK, P. (2018). Bio-Pellet Fuel from Oil Palm Empty Fruit Bunches (EFB): Using European Standards for Quality Testing. Sustainability, Vol. 10, No. 12, pp. 4443.

[3] RUGGIERO, A., VALÁŠEK, P., \& MÜLLER, M. (2016). Exploitation of waste date seeds of Phoenix dactylifera in form of polymeric particle biocomposite: Investigation on 
adhesion, cohesion and wear. Composites Part B: Engineering, Vol. 104, pp. 9-16.

[4] KRMELA, J., \& KRMELOVA, V. (2011). Tire Casings and Their Material Characteristics for Computational Modeling of Tires. In 16th International Scientific Conference Engineering for Rural Development, pp. 206-211.

[5] KRMELA, J., \& TOMANOVA, V. (2010). Microstructure of tire composite after corrosion. International Journal of Applied Mechanics and Engineering, Vol. 15, No. 2, pp. 433-439.

[6] GHOFRANI, M., ASHORI, A., REZVANI, M. H., \& GHAMSARI, F. A. (2016). Acoustical properties of plywood/waste tire rubber composite panels. Measurement, Vol. 94, pp. 382387.

[7] SIENKIEWICZ, M., JANIK, H., BORZĘDOWSKA-LABUDA, K., \& KUCIŃSKA-LIPKA, J. (2017). Environmentally friendly polymer-rubber composites obtained from waste tyres: A review. Journal of cleaner production, Vol. 147, pp. 560-571.

[8] AOUDIA, K., AZEM, S., HOCINE, N. A., GRATTON, M., PETTARIN, V., \& SEGHAR, S. (2017). Recycling of waste tire rubber: Microwave devulcanization and incorporation in a thermoset resin. Waste management, Vol. 60, pp. 471-481.

[9] MÜLLER, M., VALÁŠEK, P., \& RUDAWSKA, A. (2017). Mechanical properties of adhesive bonds reinforced with biological fabric. Journal of adhesion science and Technology, Vol. 31, No. 17, pp. 1859-1871.

[10] AZIZ, S. H., \& ANSELL, M. P. (2004). The effect of alkalization and fibre alignment on the mechanical and thermal properties of kenaf and hemp bast fibre composites: Part 1-polyester resin matrix. Composites science and technology, Vol. 64, No. 9, pp. 1219-1230.

[11] ALVES, C., SILVA, A. J., REIS, L. G., FREITAS, M., RODRIGUES, L. B., \& ALVES, D. E. (2010). Ecodesign of automotive components making use of natural jute fiber composites. Journal of cleaner production, Vol. 18, No. 4, pp. 313-327.

[12] BLEDZKI, A. K., FARUK, O., \& SAIN, M. (2012). Biocomposites Reinforced with Natural Fibers. Progress in Polymer Science, Vol. 37, pp. 1552-1596.

[13] EL-TAYEB, N. S. M., YOUSIF, B. F., \& YAP, T. C. (2006). Tribological studies of polyester reinforced with CSM 450-R-glass fiber sliding against smooth stainless steel counterface. Wear, Vol. 261, No. 3-4, pp. 443-452.

[14] PIHTILI, H., \& TOSUN, N. (2002). Effect of load and speed on the wear behaviour of woven glass fabrics and aramid fibre-reinforced composites. Wear, Vol. 252, No. 11-12, pp. 979984.

[15] KUMAR, B. R., SURESHA, B., \& VENKATARAMAREDDY, M. (2009). Effect of particulate fillers on mechanical and abrasive wear behaviour of polyamide 66/polypropylene nanocomposites. Materials \& Design, Vol. 30, No. 9, pp. 3852-3858.

[16] MÜLLER, M., RUGGIERO, A., VALÁŠEK, P. (2017). Mechanical Characterisation of Metal/Polymeric Composite Waste/Metal Sandwich Panel. Manufacturing Technology, Vol. 17, No. 4, pp. 530-536.

[17] SVOBODOVÁ, J., LYSOŇKOVÁ, I., KREJČÍ, M. (2019). Microhardness and Nanohardness Measurement of Composite Coatings Applied to Aluminium Substrate. Manufacturing Technology, Vol. 19, No. 4, pp. 700-705.

[18] NOVOTNÝ, J., LYSOŇKOVÁ, I., MICHNA, Š., NÁPRSTKOVÁ, N. (2017). Research of Application Possibilities of Selected Mechanically Alloyed Metal Powders. Manufacturing Technology, Vol. 17, No. 5, pp. 811-815.

[19] RUDAWSKA, A. (2012). Surface free energy and 7075 aluminium bonded joint strength following degreasing only and without any prior treatment. Journal of Adhesion Science and Technology, Vol. 26, No. 8-9, pp. 1233-1247.

[20] VALÁŠEK, P. (2015). Polymeric microparticles composites with waste EPDM rubber powder. Agronomy Research, Vol. 13, No. 3, pp. 723-731.

[21] VALÁŠEK, P., \& MÜLLER, M. (2014). EPDM rubber material utilization in epoxy composite systems. Agronomy Research, Vol. 12, No. 1, pp. 291-298.

[22] VAVRO, J, VAVRO, J jr., PECUŠOVÁ, B., BURGET, M. (2018). Dynamic Analysis of Lever Mechanism for Manufacturing of Raw Tyres. Manufacturing Technology, Vol. 18, No. 1, pp. 145-148.

[23] VAVRO, J jr., VAVRO, J, VAVROVÁ, A. (2019). Experimental and Numerical Modal Analysis of the Carbon Composite Plate Damaged by Cut. Manufacturing Technology, Vol. 19, No. 5, pp. 891-895. 